\title{
PARTICIPAÇÃO SOCIAL E FAMILIAR DE IDOSAS VINCULADAS A UM GRUPO DE CONVIVÊNCIA DE UMA COMUNIDADE DE BAIXA RENDA EM CURITIBA-PR
}

\section{SOCIAL AND FAMILY INVOLVEMENT OF SENIOR CITIZENS IN A SOCIAL GROUP IN A LOW INCOME COMMUNITY IN CURITIBIA-PR}

DOI: $10.22199 /$ S07187475.2015.0003.00002

Recibido: 29 de Diciembre del 2014 | Aceptado: 24 de Noviembre del 2015

\author{
ANA CLAUDIA N. S. WANDERBROOCKE 1 ; ANNELIESE M. V. WIEDEMANN 2 ; CLEIDE BUSSOLIN 3 \\ (UNIVERSIDADE TUIUTI DO PARANÁ, CURITIBA-PR, Brasil)
}

\begin{abstract}
RESUMO
Introdução: 0 Brasil vem apresentando um aumento significativo na expectativa de vida de sua população. Os idosos, assim como podem estar expostos a situações de maior vulnerabilidade, também podem contribuir significativamente para a manutenção da estrutura familiar. Objetivo: caracterizar as relações familiares e sociais de idosas participantes de um grupo de convivência de uma comunidade de baixa renda. Métodos: A pesquisa toma como base o referencial sistêmico, que parte do pressuposto da interdependência entre os membros da família e o contexto social em que as mesmas estão inseridas. Participaram 19 mulheres, sendo a média de 68 anos, integrantes de um grupo de convivência para idosos, realizado no Centro de Referência de Assistência Social (CRAS), que atende a uma comunidade de baixa renda na região metropolitana de Curitiba-PR. Resultados: A partir dos dados obtidos, foi possível perceber a importância atribuída a vida familiar pelas participantes, que a consideraram como organizadora de suas vidas. As idosas exerciam papel central na família, tanto pelo desempenho das tarefas domésticas, quanto de orientações e cuidados, pois se mantinham saudáveis e ativas. Conclusão: Para a maioria das entrevistadas o CRAS tem um papel socializador, proporcionando o sentimento de pertencimento, devido a identidade grupal.
\end{abstract}

PALAVRAS-CHAVE: Idoso; Comunidade de baixa renda; Relações familiares; Relações sociais.

\section{ABSTRACT}

Introduction: Life expectancy in Brazilian population has increased considerably in the last years. Senior citizens, although exposed to situations of greater vulnerability, al so contribute significantly to the maintenance of family structure. Objective: To characterize the family and social relationships of senior citizens in a social group living in a low income community. Method: The research builds upon the systemic reference premise of interdependency between family members and the social context in which they are embedded. Nineteen women with an age average of 68 participated in the research. They are members of a support group for the elderly, held at the Reference Centre for Social Assistance (CRAS), which serves a low-income community in the metropolitan region of Curitiba-PR. Results: Results show senior citizens are key members of family life. They exercised central roles in the family, from the performance of household tasks to guidance and care since they remained healthy and active. Conclusions: It was also observed that for most subjects the CRAS has a socializing role, providing a sense of belong ing due to group identity.

KEY WORDS: Senior citizens, low-income community family relations, social relations 


\section{INTRODUÇÃO}

O Brasil vem apresentando número crescente de idosos e um aumento significativo na expectativa de vida de sua população. Porém, um dos aspectos que diferencia o Brasil de países desenvolvidos quanto ao envelhecimento populacional é que nestes países o processo ocorreu de forma gradativa. Outra diferença é que os países desenvolvidos enriqueceram antes de envelhecer e o Brasil ainda em desenvolvimento, lida com realidades muito diferentes dentro de sua extensão territorial. Da mesma forma que se verifica grandes avanços em termos de qualidade de vida, convive-se com um processo de crescimento econômico desigual, com a existência de bolsões de pobreza e favelas em cidades que prosperam em outros aspectos, como estrutural e de serviços.

Apesar de a qualidade de vida ser definida pela Organização Mundial de Saúde (WHO, 1946) como uma condição subjetiva, pode-se dizer que viver em comunidades de baixa renda afeta negativamente 0 processo de desenvolvimento humano por expor as pessoas a um maior número de fatores adversos. Analisando as comunidades a partir da ótica da complexidade (Morin, 2007), considera-se a interdependência entre fatores sociais, familiares e pessoais. Dessa forma, a maneira como se vive a velhice está diretamente relacionada com a condição familiar e as influências que a comunidade e sociedade exercem sobre ela.

$\mathrm{Na}$ nossa cultura, muito se valoriza 0 envelhecer em família e cria-se a expectativa de que a família possa dar conta das demandas provenientes do processo de envelhecimento de seus membros (Silva et. al, 2015; Silva, Vilela, Oliveira \& Alves, 2015). Esta expectativa no entanto, nem sempre leva em consideração as condições socioculturais que as afetam. Aquelas que estão inseridas em comunidades de baixa renda, o foco deste trabalho, geralmente convivem com problemas como: alta densidade populacional, precariedade de moradias, delinquência juvenil, tráfico de drogas, desemprego, gravidez na adolescência, violências, entre outros. Quando possuem membros idosos as vulnerabilidades podem se manifestar nas limitações impostas pela idade, saúde debilitada e dependência, em interdependência com os fatores anteriormente citados (Penso \& Morais, 2009).

Assim como os idosos podem estar expostos a situações de maior vulnerabilidade, também podem contribuir significativamente para a manutenção da estrutura familiar. Isso porque, as pessoas que estão envelhecendo na atualidade têm a sua disposição mais recursos para lidar com as limitações de saúde, levando-as a viver melhor, por mais tempo e numa posição mais ativa na família (Vera et al, 2015).

Dados do senso brasileiro mostram que a renda dos idosos aumentou, contribuindo para o sustento das gerações mais jovens, principalmente, em famílias de baixa renda (Camarano, 2001). Em pesquisa realizada com idosos trabalhadores informais, Coutrim (2006) demonstrou que, enquanto provedores, esses idosos permanecem chefes de família, o que lhes confere maior poder de decisão, orgulho do trabalho e da posição que ocupam nas relações familiares. Esses dados de pesquisa estão em consonância com o IBGE (2007) que indica 0 aumento de idosos como responsáveis e chefes de domicílio. Essa ocorrência significa que sustentam ou ajudam no sustento da geração mais jovem. Já a pesquisa de Teixeira e Rodrigues (2009) concluiu que os idosos ajudam mais as gerações mais novas do que são por elas ajudados.

Para que haja o contínuo intercâmbio entre os idosos e os demais membros da 
família, Couto, Novo e Koller (2009) enfatizam a reciprocidade nas trocas de apoio como um fator importante na avaliação dos aspectos funcionais da rede familiar e social da pessoa idosa. Assim, quanto maior a reciprocidade, mais funcional a rede costuma ser considerada pelos idosos, com mais potencialidade para diminuir o impacto de eventos estressantes e maior a resiliência manifestada em situações adversas. Na mesma direção estão os dados de Guedea et. al. (2006), que indicam aumento do bem-estar subjetivo e da satisfação com a vida entre idosos que dão e recebem apoio aos outros. É um aspecto importante a se considerar, pois, devido à crescente fragilidade, o idoso pode se ver impedido de dar na mesma medida em que recebe dos membros de sua rede e se considerar um peso para os demais, situação que tem o potencial de gerar sentimentos negativos e de afetar sua saúde (Batistoni, et al. 2015).

Além dos dados que indicam a participação cada vez maior dos idosos no cotidiano familiar, com base na Política Nacional do Idoso (Brasil, 1994), entende-se que todas as ações de saúde devem objetivar ao máximo manter o idoso na comunidade junto com a sua família, trabalhando com suas reais necessidades $e$ disponibilidades e potencializando sua rede de apoio social. Destaca-se a importância da permanência do idoso na rotina familiar e na vida em comunidade como fatores fundamentais para manutenção de seu equilíbrio físico e mental. Proposta que se resume em uma busca não simplesmente da longevidade, mas da garantia de vida com qualidade.

Considera-se importante salientar que a noção de família é um produto histórico e ideologicamente situado, portanto, há diferentes conceitos e nenhum capaz de dar conta das diferentes maneiras de entende-la e vive-la. A noção de família regula a participação das pessoas dentro e fora do sistema familiar e conduz a diferentes práticas sociais baseadas em direitos, deveres, modo de pensar, conduzir a vida, cuidar do outro, amar. Algumas destas maneiras tem servido a interesses específicos e discursos dominantes em relação as questões de gênero, geração, raça e/ou classe social (Martins, McNamee \& Guanaes-Lorenzi, 2015).

Portanto, ao pensar a família é preciso levar em conta as transformações socioculturais a que está sujeita por ser um sistema aberto, assim como as reestruturações necessárias para manter a continuidade e intensificar 0 crescimento psicossocial de cada um de seus integrantes (Minuchin, 1982), inclusive dos idosos, por se entender que nesta etapa da vida também há a possibilidade de ganhos e crescimento e não somente perdas (Neri, 2007).

Diante do exposto, 0 objetivo da pesquisa foi 0 de caracterizar as relações familiares e sociais de idosas participantes de um grupo de convivência de uma comunidade de baixa renda. A pesquisa toma como base o referencial sistêmico, que parte do pressuposto da interdependência entre os membros da família e o contexto social em que as mesmas estão inseridas. Esta pesquisa prima pela prerrogativa do protagonismo da pessoa idosa, vista como agente de conhecimento e exercendo papel ativo no processo de construção de um meio eficaz para o desenvolvimento humano.

\section{MÉTODO}

Os aspectos metodológicos desta pesquisa foram guiados pelo pressuposto de que 0 conhecimento é resultado de um processo infinito de construção de significados em torno dos aspectos sensíveis da realidade, possível pelas inter-relações estabelecidas entre pesquisador e participantes.

Participaram 19 mulheres, com idades entre 59 e 86, sendo a média de 68 anos, 
integrantes de um grupo de convivência para idosos, oferecido por um Centro de Referência de Assistência Social (CRAS) na região metropolitana de Curitiba-PR, que atende a uma comunidade de baixa renda.

A comunidade em questão teve seu inicio em fevereiro de 1990, por pessoas provenientes do seu próprio município e de municípios vizinhos que formaram um contingente de 25 famílias nas primeiras semanas. Após essa primeira ocupação, as pessoas começaram a cercar um pedaço de chão o denominando como seu lote $e$ fazendo barracos com restos de madeiras e cobertos com lonas plásticas.

Com 0 tempo, a comunidade desenvolveu-se e com isto veio 0 investimento municipal e estadual em infraestrutura. De acordo com um levantamento realizado por Araújo (2001), constatou-se que, na ocasião, a comunidade contava com duas escolas públicas, um posto de saúde e duas farmácias, uma linha de ônibus até um terminal rodoviário no centro de Curitiba. Nesta época, $70 \%$ dos moradores possuía água encanada e a luz elétrica já era bastante acessível, porém não havia sistema de esgoto. Atualmente, a localidade conta com cerca de quinze mil pessoas e apesar dos progressos, ainda é conhecida como uma comunidade que apresenta sérios problemas sociais como violência, presença de tráfico de drogas, entre outros.

Inicialmente as pesquisadoras entraram em campo realizando contato com a coordenadora do CRAS da região a fim de esclarecer sobre os objetivos da pesquisa. Uma vez autorizada a realização da mesma, foi dado início ao contato com as idosas, por meio da participação nas atividades semanais propostas pela pessoa responsável pelo grupo de convivência. Os objetivos da pesquisa foram apresentados no grupo, seguido do convite à participação na pesquisa. Posteriormente, cada idosa foi abordada de forma individual, para que 0 convite fosse reiterado. Das 25 participantes, 19 demonstraram interesse em fazer parte da pesquisa e com estas, foi agendado horário durante ou após as atividades do grupo, que eram de costura, pintura, confecção de fuxicos para almofadas, realização de bingos, sorteios e atividades físicas.

Antes do início da coleta de dados, as pesquisadoras retomavam o objetivo da pesquisa e assim que obtinham 0 aceite, solicitavam a assinatura do Termo de Consentimento Livre e Esclarecido (TCLE).

0 instrumento consistiu em uma entrevista estruturada, contendo 19 perguntas fechadas e 4 abertas, as pesquisadoras liam as questões e anotavam as respostas das participantes no instrumento. A coleta de dados ocorreu entre os meses de abril a junho de 2013. Os dados coletados por meio das questões fechadas foram submetidos à estatística descritiva e os das questões abertas foram categorizados, utilizando-se o referencial da análise de conteúdo proposto por Bardin (2011).

A pesquisa cumpriu as especificações da Resolução $n^{\circ} 466$, de 12 de dezembro de 2012, do Conselho Nacional da Saúde, que regulamenta as pesquisas envolvendo seres humanos e o projeto foi submetido à análise de um Comité de Ética em Pesquisa, tendo sido aprovado com o parecer número 05.02.201/2012.

\section{RESULTADOS E DISCUSSÃO}

Quanto à escolaridade, $53 \%$ (10) eram analfabetas, $37 \%$ (7) tinham o primeiro grau incompleto, $10 \%$ (2) tinham o primeiro grau completo. Dados que refletem a dificuldade de acesso à escola no Brasil há algumas décadas, principalmente para os moradores da zona rural, local de origem de parte das integrantes desta pesquisa. 
Entre as participantes, $48 \% \quad(9)$ trabalharam na lavoura, $21 \%$ (4) como diarista, 16\% (3) do lar, 5\% (1) costureira, e $5 \%$ (1) auxiliar de limpeza. Somente uma das participantes denominou-se enfermeira, mas explicou que na época não era necessária a realização de um curso formal, mas a prática da atividade.

Em relação à renda, entre as que recebiam aposentadoria, $26 \%$ (5) eram pensionistas, $16 \%$ (3) se aposentaram por tempo de serviço, $10 \%$ (2) recebiam aposentadoria social e $5 \%$ (1) era aposentada por invalidez. Entre as demais, $21 \%$ (4) recebiam auxílio da família e $21 \%$ (4) tinham outro tipo de renda. Nesse sentido, pode-se dizer que todas tinham amparo financeiro, sendo que $79 \%$ (15) recebiam até um salário mínimo e somente $21 \%$ (4) recebiam dois salários. Os dados desta pesquisa coincidem com os do IBGE (2007), que apontam que a renda do idoso depende principalmente dos benefícios previdenciários.

Quanto à distribuição da renda 68\% (13) das participantes apontaram a sua renda como principal fonte de manutenção da $\begin{array}{lll}\text { casa, } & 10,5 \% & (2), \quad \text { contribuíam }\end{array}$ igualitariamente com os outros membros da família, $10,5 \%$ (2) contribuíam em menor parte e $10,5 \%$ (2) não possuíam renda própria.

Todas as participantes tiveram filhos, $30 \%$ (6) tiveram até três filhos e as demais $70 \%$ (13) quatro filhos ou mais. A composição familiar atual revelou ampla variação, de 1 a 25 pessoas além da participante. Porém, em alguns casos, os membros da família extensa foram computados por morarem no mesmo terreno e haver grande proximidade no convívio. Apesar de não ter sido perguntado o motivo da moradia conjunta, é comum verificar-se nesta e em outras comunidades o terreno dos pais ou avós, os primeiros moradores, subdividido para dar lugar à residência dos filhos adultos e/ou netos, presumivelmente pela falta de recursos destes para adquirir o próprio.

Este dado confere com a pesquisa realizada por Freitas, Rocha, Silva e Breda (2005) que apontam que da grande maioria de idosos responsáveis pelos domicílios, em todo o país, $64 \%$ deles mora com ou sem cônjuge, mas com filhos e outros parentes na mesma casa. Essa proximidade pode garantir ao idoso um papel, um lugar na família, que 0 ajuda a manter sua identidade, permitindo contribuir com os demais, tanto no sentido financeiro como pela realização de serviços e apoio afetivo, como será visto mais adiante.

No quesito situação conjugal atual $63 \%$ (12) das idosas eram viúvas, $27 \%$ (5) eram casadas, $5 \%$ (1) participante era separada, e $5 \%$ (1) idosa era solteira. Da mesma forma que as estatísticas nacionais, as mulheres por viverem mais tempo também vivem mais a condição de viuvez (Costa, Porto \& Soares, 2003). Dado que denota a importância da manutenção dos vínculos familiares e sociais para que a pessoa idosa não passe a uma situação de isolamento.

No que se refere à condição do domicilio 95\% (18) das participantes disseram ter residência própria e somente $5 \%$ (1) participante morava em área ainda não regulamentada. Em relação à avaliação qualitativa do domicílio, $84 \%$ (16) das participantes disseram que a casa era excelente, $5 \%$ (1) muito boa, $5 \%$ (1) boa e $5 \%$ (1) razoável.

0 fato de mais de $80 \%$ (15) das participantes apontarem seus domicílios como excelentes é muito significativo, e pode-se inferir que esteja relacionado a própria história da comunidade onde a pesquisa foi realizada. A comunidade em questão começou a existir em torno de uma área de ocupação. Consequentemente, seus moradores conviveram durante anos com sérios problemas como precariedade de moradia, segurança, acesso à educação, 
saneamento e saúde. Nas últimas décadas, porém, acompanhando o crescimento do país a comunidade vivenciou progressos significativos, refletidos na qualidade das moradias. Dados que ficaram evidentes com os comentários das participantes durante a entrevista, pois as mesmas disseram estar muito satisfeitas no bairro, verbalizvaam que não sentiam falta de nada e suas casas seriam como "palácios".

As participantes quando questionadas a respeito da condição de saúde, $53 \%$ (10) responderam que tem a saúde razoável, $16 \%$ (3) boa, 26\% (5) excelente e apenas $5 \%$ (1) disse ter saúde precária. Estes dados podem estar relacionados a fatores culturais, pois a mulher tradicionalmente assume o papel de cuidadora, tanto de sua família, de casa, do marido, e isto se reflete também em sua saúde. Este pensamento vai ao encontro do estudo de Gomes (2007), que constata que mulheres possuem 0 hábito de se cuidar mais procurando mais os serviços de atenção primária à saúde que os homens. Além deste aspecto relacionado ao gênero, Batistoni et al. (2015) em estudo sobre a identificação etária, concluíram que a concepção de velhice ainda continua atrelada à piores condições de saúde e os idosos que mantém boa percepção de sua saúde tendem a atribuir-se uma idade subjetiva menor o que é considerado pelas autoras como indicador de bem-estar e como uma estratégia de regulação do self.

Em relação à religiosidade 84\% (16) das participantes eram católicas, 10,5 (2) evangélicas, e 5,5\% (1) apontaram outra religião, porém, não a especificaram. Em relação à participação religiosa, $11 \%$ (2) das idosas praticavam diariamente, $58 \%$ (11) semanalmente, $26 \%$ (5) mensalmente e $5 \%$ (1) nunca foram. Diante dos dados obtidos pode-se dizer que a religião tem um importante papel, não importando qual segmento $_{2}$ pois todas apresentaram algum tipo de vínculo com instituições religiosas, mostrando grande assiduidade.
Para levantar a participação familiar das idosas, foi questionado em relação à distribuição de tarefas entre as idosas e os demais familiares residentes na mesma casa. $84 \%$ (16) das idosas limpavam a casa e cozinhavam, $79 \%$ (15) eram responsáveis por lavar e passar a roupa, 64\% (13) saíam para comprar comida, 63\% (12) cuidavam do jardim/horta, $52 \%$ (10) cuidavam dos netos, $26 \%$ (5) orientavam as outras pessoas da casa na realização das tarefas, $26 \%$ (5) trabalhavam na manutenção do imóvel, $10 \%$ (2) cuidavam de pessoas adultas dependentes, e $5 \%$ (1) eram responsável pela segurança.

As atribuições das participantes denotam claramente a manutenção na velhice da divisão sexual do trabalho que separa o que é trabalho de homem do que é trabalho de mulher (Silva, Arantes e Ferreira, 2012), sendo este último associado ao cuidado com as crianças e a manutenção e cuidado com as outras pessoas, trabalho que apresenta uma conotação natural, maternal e que não recebe 0 mesmo destaque hierárquico e de remuneração que os homens. Como exceção, algumas indicaram realizar a manutenção do imóvel, tarefa tradicionalmente atribuída ao homem, porém, como a maioria das participantes era viúva, pode-se pensar que a realizavam pela ausência do marido ou disponibilidade de contar com outra pessoa para tal. Como as idosas permaneciam por mais tempo em suas residências em comparação ao restante da família, fazia com que ficassem encarregadas pelo maior número de tarefas.

Em relação aos netos verificou-se que $52 \%$ (10) das idosas eram responsáveis pelos cuidados dos mesmos. Além da divisão sexual do trabalho anteriormente citada, o fato pode estar relacionado à realidade social da comunidade que não dispunha de número suficiente de creches para suprir a demanda das famílias, necessitando que as avós se comprometessem nos cuidados aos netos. Apesar desta limitação imposta pela rede de 
assistência social, entende-se que a proximidade entre avós e netos possibilitava trocas afetivas, transmissão de valores, fortalecimento de vínculos e interação social tanto com os netos, como com os filhos.

Outra tarefa que se mostrou relevante de $63 \%$ (12), foi cuidar de jardim/horta, o que pode estar relacionado ao fato de a maioria das idosas entrevistadas terem origem rural, e tal atividade pode trazer algum tipo de prazer ou satisfação ao serem executadas.

Estes dados da pesquisa vão ao encontro com o estudo de Ferreira (2010), que aponta o envelhecimento visto como uma fase ativa, na qual os idosos trabalham em seus lares, nos afazeres domésticos, cuidam da casa, cozinham, fazem compras, cuidam dos netos, ajudam os familiares e administram suas vidas e é permeada por um discurso de conteúdos positivos. Considera-se que conseguir manter a funcionalidade e a independência é um passo importante para se atingir um envelhecimento ativo e com qualidade, desde que seja uma possibilidade de escolha e não por uma falta de investimento social ou pela naturalização da função social das mulheres idosas como cuidadoras.

Referente ao significado da família, observou-se que 100\% (19) participantes, consideravam a família como muito importante, verbalizando que sem elas não seriam nada, ou ainda que a família é 0 alicerce da vida. Neste sentido, Sarti (2008) pontua que a primeira instituição pela qual 0 ser humano tem conhecimento sobre a noção dos valores e da moral é a família, é nela que surge 0 sentimento de pertencimento e identidade pessoal e isso reflete diretamente no convívio comunitário. Por outro lado, as transformações sociais ocasionaram mudanças também na concepção de família, surgindo novas composições familiares e consequentemente novos padrões, condutas e hábitos.
Estas novas configurações são observadas em algumas famílias das idosas participantes da pesquisa, nas quais famílias nucleares e extensas conviviam juntas, mas não necessariamente na mesma casa, mas sim no mesmo terreno ou muito próximas. Fato que requer certo grau de flexibilidade para adaptação e manejo de conflitos que possivelmente possam surgir nas relações intergeracionais.

No que se refere ao que sente falta em sua família, $40 \%$ (6) das idosas, evidenciaram a falta de alguém, como filho ou marido que faleceram ou que moram longe, $13 \%$ (2) das idosas demonstraram 0 desejo de que algum familiar deixasse de beber e $7 \%$ (1) idosa enfatizou o desejo de que o neto saísse da cadeia, $7 \%$ (1) relatou que não sabia, pois cada um tem a sua vida, $7 \%$ (1) verbalizou que não sentia falta de nada, pois familiares sempre ligavam e a visitavam.

Em relação aos fatores estressantes, 0 que apresentou a maior incidência foi a morte de familiares, que foi mencionado por $60 \%$ (11) das participantes, a hospitalização apareceu como o segundo evento estressor para 40\% (7) das idosas. A mudança de cidade foi apontada por 25\% (5) das participantes. Como outros eventos estressantes encontrou-se a perda de emprego 15\%(3), doença 15\% (3), e uso de drogas 15\% (3), separação/divórcio 10\% (2), violação de leis $10 \%$ (2), abuso/violência 10\% (2), uso de álcool 10\% (2), assalto/roubo $5 \%(2)$.

Os dados supracitados remetem as perdas mais comuns nesta fase da vida como a do cônjuge e problemas de saúde, neste caso apontado como estressores relacionados à hospitalização. Além destes aspectos esperados em função da idade, chamou a atenção estressores citados intimamente relacionados à violência estrutural que afeta as famílias e consequentemente a qualidade do envelhecimento das participantes. Cabe 
salientar a importância de se levar em consideração a interdependência dos aspectos pessoais, familiares e sociais quando se busca oferecer melhores condições para o envelhecimento.

No que se refere a sua principal função dentro da família $53 \%$ (10) idosas, informaram que se sentiam a coluna, 0 esteio, ou ainda a estrutura de sua família, $37 \%$ (7) idosas apontaram que ajudavam a família no que podiam, tanto em tarefas práticas como orando pelo bem estar dos familiares e apenas $10 \%$ (2) participantes, informaram que recebiam mais ajuda de seus familiares do que podiam oferecer. Mais uma vez, os dados demonstram que estas mulheres percebiam-se envolvidas e ocupando função de responsabilidade em relação aos seus familiares.

A pesquisa buscou conhecer também como se dava a participação social das idosas, para isto, inicialmente foi perguntado quanto à prática de atividades esportivas. Como resposta obteve-se que $68 \%$ (13) das participantes praticavam alguma atividade semanalmente ou diariamente, $32 \%$ (6) praticavam ocasionalmente ou nunca praticaram.

Quanto a atividades que proporcionam algum tipo de aprendizagem foi constatado que $53 \%$ (10) das idosas nunca se envolveram, $32 \%$ (6) tinham atividades semanais, e $15 \%$ (3) não souberam responder. De acordo com Unicovsky (2004), a educação nessa faixa etária seria um meio para vencer os desafios impostos aos idosos pela idade e pela sociedade, propiciando-lhes o aprendizado de novos conhecimentos e oportunidades para buscar seu bem-estar físico e emocional. Este processo deveria possibilitar ao idoso, reflexões em torno do seu ambiente concreto, das suas vivências cotidianas e da sua realidade mais próxima. Quanto às atividades realizadas no grupo de convivência, pode-se observar que proporcionava interação com 0 grupo, diversão e até mesmo uma função terapêutica. Observou-se que havia uma forte identidade grupal, pois se tratavam pelo nome e verbalizavam durante a entrevista a importância de terem esse espaço para frequentar. Porém, por serem atividades já conhecidas a maioria não as considerou como envolvendo aprendizagem.

Em relação ao lazer, $21 \%$ (4) das idosas apontaram como principal atividade ir ao CRAS, 21\% (4) passear, seguido de ver televisão $16 \%$ (3), ir a festas e bingos $11 \%$ (2), ir à igreja, fazer crochê/tricô, cantar e conversar ficaram empatados $5 \%$ (1). Somente $11 \%$ (2) das participantes não praticavam nenhuma atividade que acreditavam ser de lazer.

Quanto às atividades culturais 68\% (16) disseram que nunca frequentavam ou frequentavam raramente e $16 \%$ (3) mensalmente. Sendo assim, pode-se perceber que as atividades oferecidas pelo CRAS assumiam um lugar de importância para as participantes, que possuíam poucas oportunidades de participar de outros espaços de lazer oule cultural. Neste contexto, percebe-se que o grupo de convivência frequentado pelas idosas, tinha um significado importante frente à participação social das mesmas, pois fazia com que elas saíssem de casa, desenvolvessem diversos tipos de atividades, conhecessem novas pessoas e lugares, assim como compartilhassem experiências sobre um momento da vida que envolve muitas mudanças $e$ ressignificações.

Foi questionado como era viver na comunidade ao que $89 \%$ (17) das idosas responderam gostar de morar no local, considerando-o como sua segunda casa, ou uma irmandade. 0 total de $11 \%$ (2) participantes entrevistadas relataram ter medo da violência, pelo fato de terem sofrido a perda de um ente querido dentro da comunidade. Apesar da preocupação 
com a violência, esses dados confirmam 0 que Ochoa, Olaizola, Espinosa e Martínez (2004) apontam, que o sentimento de pertencimento a um grupo, dentro da comunidade gera atitudes de motivação, de participação, de confiança, ou seja, um desejo de atuar com os demais. Da mesma maneira, Elvas e Moniz (2010) afirmam que a nível individual, um maior sentimento de comunidade traduz-se em níveis mais elevados de bem estar, qualidade e satisfação de vida, sentido de justiça e capital social, menor solidão e isolamento.

\section{CONSIDERAÇÕES FINAIS}

0 presente artigo buscou caracterizar as relações familiares e sociais de idosas participantes de um grupo de convivência de uma comunidade de baixa renda. A partir dos dados obtidos, foi possível perceber a importância atribuída à vida familiar para as participantes, que a consideraram organizadora de suas vidas. Como se mantinham saudáveis e ativas exerciam papel central na família, tanto pela posição financeira, como pelo desempenho de tarefas domésticas de orientações $\mathrm{e}$ cuidados.

Apesar de relatarem satisfação com a própria saúde e com as questões estruturais da vida, como condição de moradia e recursos da comunidade, os dados evidenciam que as idosas têm suas vidas afetadas pelas deficiências de equipamentos sociais na localidade, como creches para os netos e restrição de oportunidade de lazer e cultura. Além disso, os dados evidenciaram que problemas sociais como a violência que afeta os jovens também se refletem em fonte de sofrimento e prejuízo na saúde do idoso. Desta forma, considera-se fundamental que espaços de acolhimento social sejam mantidos e incentivados para que a pessoa idosa tenha acesso a fontes de apoio e orientações quanto aos serviços de saúde disponíveis.
Outro aspecto que merece destaque é a importância de se manter e ampliar propostas voltadas ao público idoso nas comunidades para que possam conciliar vida doméstica, atividades que possibilitem 0 desenvolvimento de habilidades, lazer e participação social. Ao mesmo tempo em que se viam mantendo papel organizador da vida familiar, as participantes demonstraram interesse em ocupar o tempo livre com atividades que possibilitavam novas aprendizagens. Entende-se que estes espaços de convivência além de promoverem a afirmação da identidade, podem também incentivar a participação e 0 protagonismo social da pessoa idosa.

Entende-se que a amostra deste estudo se restringiu a um grupo de idosas que mantém condições físicas e cognitivas para a participação em um grupo de convivência, não representando a totalidade de moradoras idosas da comunidade. Sendo assim, sugere-se que outras comunidades sejam avaliadas no sentido de se verificar qual a possibilidade de participação e de integração de pessoas idosas. 


\section{REFERÊNCIAS}

Araújo, S.G (2001). O fenômeno de favelização da Vila Zumbi dos Palmares Colombo. Trabalho de Conclusão de Curso, apresentado na Universidade Tuiuti do Paraná, Curitiba-PR, Curso de Geografia com Enfase em Geoprocessamento.

Bardin, L. (2011). Análise de conteúdo. São Paulo: Edições 70.

Batistoni, S.S.T.; Prestes, S.M.; Cachioni, M.; Falcão, D.V.S.; Lopes, A.; Yassuda, M.S. et. al. (2015). Categorização e identificação etária em uma amostra de idosos brasileiros residentes na comunidade. Psicol. reflex. crit; 28(3): 511-521.

Brasil. (1994). Lei no 8.842 de 4 de janeiro de 1994. Dispõe sobre a Política Nacional do Idoso. Brasília, Ministério do Desenvolvimento Social e Combate à Fome.

Camarano, A.A. (2001). Envelhecimento da população brasileira: problema para quem? Bahia Análise \& Dados 10(4): 36-48.

Costa, E. F. A.; Porto, C. C.; Soares, A. T. (2003). Envelhecimento populacional brasileiro e 0 aprendizado de geriatria e gerontologia. Revista da UFG, Vol. 5, No. 2, dez. Acesso em 25/03/2013, www.proec.ufg.br.

Coutrim, R. M.; (2006). Idosos trabalhadores: perdas e ganhos nas relações intergeracionais. Sociedade e Estado, Brasília, 21(2): 367-390.

Couto, M.C.P.; Novo, R.F.; \& Koller, S.H. (2009). Relações entre rede de apoio social, bem-estar psicológico e resiliência na velhice. En Falcão, D.V.S \& Araújo, L.F. (orgs.) Psicologia do envelhecimento: relações sociais, bemestar subjetivo e atuação profissional em contextos diferenciados (pp.45-66). Campinas, SP: Alínea.

Elvas, S. \& Moniz, M. J. V. (2010). Sentimento de comunidade, qualidade e satisfação de vida. Análise Psicológica, 3(XXVIII), 451-
464Gil, A. C. (1991) Como elaborar projetos de pesquisa. São Paulo: Atlas.

Freitas, D.G.; Rocha, M.A.S; Silva, R.F.S \& Breda, V. (2005). Idoso provedor de família. Trabalho de Conclusão de Curso, apresentado nas Faculdades Integradas Antônio Eufrásio de Toledo, curso de Serviço Social, Presidente Prudente-SP.

Guedea, M.T.D.; Albuquerque, F.J.B.; Tróccoli, B.T.; Noriega, J.A.V.; Seabra, M.A.B.; \& Guedea, R.L.D. (2006). Relação do bem-estar subjetivo, estratégias de enfrentamento e apoio social em idosos. Psicologia Reflexão e Critica, 19(2):301-308.

Instituto Brasileiro de Geografia e Estatística. (2007). IBGE divulga indicadores sociais dos últimos dez anos. Acesso em: 30/06/2008, http:www.ibge.gov.br/home/ presidência/noticias/noticia_impressao.p hp?id_noticia=987

Martins, P.P.S.; McNamee, S. \& GuanaesLorenzi, C. (2015). Família como realização discursiva: uma explicação relacional. Nova Perspectiva Sistêmica, 52, 9-24.

Minuchin, S. (1982). Família: funcionamento e tratamento. Porto Alegre: Artes Médicas.

Morin, E. (2007). Introdução ao pensamento complexo. ( $3^{\mathrm{a}}$. ed.) Porto Alegre: Sulina. Ochoa, G.M.; Olaizola, J.H.; Espinosa, L.M.C.; Martínez, M.M (2004). Introduccion a la Psicología Comunitaria. Ed. Uco. Barcelona. Espanã.

Neri, A. L. (2007). Qualidade de vida na velhice: Um enfoque multidisciplinar. Campinas, SP: Alínea.

Ochoa, G. M.; Olaizola, J.; Espinosa, L. M. \& Martínez, M. (orgs). Introducción a la psicología comunitaria. Barcelona: Editorial UOC.

Penso, M.A.; \& Morais, I.A. (2009). O ciclo da violência em famílias com idosos. In:

Teixeira, S. M. \& Rodrigues, V.S. (2009). Modelos de família entre idosos: famílias restritas ou extensas? Revista Brasileira de Geriatria e Gerontologia, 
12(2). Acesso em 12/05/10, www.scielo.br.

Sarti , C. A. (2008). Famílias enredadas. In: Acosta, A. R.; Vitale, M. A.(orgs.) Famílias: Redes, Laços e Políticas Públicas. 4.ed. São Paulo: Cortez.

Silva, D.M.; Vilela, A.B.A.; Nery, A.A.; Duarte, A.C.S.; Alves, M.R. \& Meira, S.S.(2015). Dinâmica das relações familiares intergeracionais na ótica de idosos residentes no Município de Jequié (Bahia), Brasil. Ciênc. saúde coletiva, 20(7): 2183-2191.

Silva, C.; Arantes, R. \& Ferreira, V. (2012). Divisão sexual e divisão racial do trabalho. In: Silva, C; Arantes, R; Ferreira. Nosso Trabalho Sustenta o Mundo. ed. 02. Recife: SOS Corpo, 2012. $92 \mathrm{p}$

Silva, D.M.; Vilela, A.B.A.; Oliveira, D.C. \& Alves, M.R. (2015). A estrutura da representação social de família para idosos residentes em lares intergeracionais. Rev. enferm. UERJ, 23(1): 21-26.

Unicovsky, M. A. R. (2004). A educação como meio para vencer desafios impostos aos idosos. Revista Brasileira de

Enfermagem. vol.57 n.2 Brasília Mar./ Apr.

Sarti , C. A. (2008) Famílias enredadas. En Acosta, A. R.; Vitale, M. A.(orgs.) Famílias: Redes, Laços e Políticas Públicas. 4.ed. São Paulo: Cortez.

Vera, I.; Lucchese, R.; Nakatani, A.Y.K.; Sadoyama, G.; Bachion, M.M.; Silva, V. et al. (2015). Fatores associados à disfuncionalidade familiar em idosos não institucionalizados. Texto-contexto Enfermagem, 24 (2). Acesso em 19/11/2015 em http://dx.doi.org/10.1590/010407072015001602014

WHO. World Health Organization. (1946). Constitution of the World Health Organization. Basic Documents, WHO, Genebra. 